\title{
Effects of a Calcium Phosphate-Coated and Anodized Titanium Surface on Early Bone Response
}

\author{
Jung-Woo Koh, DDS, MSD, PhD¹/Young-Sung Kim, DDS, MSD, $\mathrm{PhD}^{2}$ / \\ Jae-Ho Yang, DDS, MSD, PhD $3 /$ In-Sung Yeo, DDS, MSD, PhD 4
}

\begin{abstract}
Purpose: The aim of this study was to evaluate the effectiveness of a calcium phosphate $\left(\mathrm{CaPO}_{4}\right)$-coated and anodized titanium surface in vitro and in vivo. Materials and Methods: A turned surface was employed as a negative control. A sandblasted/acid-etched surface and an anodized surface were used as positive controls, and a $\mathrm{CaPO}_{4}$-coated and anodized (CPA) surface was investigated as the experimental group. Surface characteristics were analyzed with field emission scanning electron microscopy, energy dispersive spectroscopy, and confocal laser scanning microscopy. In vitro osteoblastic differentiation was evaluated by alkaline phosphatase assay. In vivo bone response was analyzed using bone-to-implant contact (BIC) ratios and bone area (BA) of 2- and 4-week specimens obtained from six rabbits. Results: The means and standard deviations for average height deviation $\left(S_{a}\right)$ and developed surface area ratio $\left(S_{d r}\right)$ were $0.32 \pm 0.03 \mu \mathrm{m}$ and $3.6 \% \pm 1.5 \%$ for the turned group, $1.36 \pm 0.11 \mu \mathrm{m}$ and $56.7 \% \pm 16.1 \%$ for the sandblasted/acid-etched group, $0.68 \pm 0.02 \mu \mathrm{m}$ and $50.9 \% \pm 2.9 \%$ for the anodized group, and $0.67 \pm 0.11 \mu \mathrm{m}$ and $50.0 \% \pm 16.9 \%$ for the CPA group. There were no significant differences in alkaline phosphatase activity among the groups at 7 and 14 days. In the in vivo experiment, the CPA group exhibited a significantly higher BIC ratio than the turned group, and the anodized and CPA groups showed significantly higher BA values than the others after 2 weeks. At 4 weeks, there was no significance in either BIC ratios or BA values among the groups. Conclusion: A $\mathrm{CaPO}_{4}$ coating on an anodized surface may induce rapid osseointegration at the bone-implant interface and more bone formation near the implant surface. INT J ORAL MAXILLOFAC IMPLANTS 2013;28:790-797. doi: 10.11607/jomi.2783
\end{abstract}

Key words: calcium phosphate, dental implants, osseointegration, oxidation, surface properties

A though turned-surface implants have provided successful results, the desire to establish rapid

\footnotetext{
${ }^{1}$ Clinician, Department of Prosthodontics, School of Dentistry and Dental Research Institute, Seoul National University, Seoul, Korea.

${ }^{2}$ Assistant Professor, Department of Periodontology, University of Ulsan College of Medicine and Asan Medical Center, Seoul, Korea.

${ }^{3}$ Professor Emeritus, Department of Prosthodontics, School of Dentistry and Dental Research Institute, Seoul National University, Seoul, Korea.

${ }^{4}$ Assistant Professor, Department of Prosthodontics, School of Dentistry and Dental Research Institute, Seoul National University, Seoul, Korea.
}

Jung-Woo Koh and Young-Sung Kim contributed equally to this work.

Correspondence to: Dr In-Sung Yeo, Department of Prosthodontics, School of Dentistry and Dental Research Institute, Seoul National University, 101 Daehak-ro, Jongno-gu, Seoul 110-749, Korea. Fax: +82-2-2072-3860. Email: pros53@ snu.ac.kr

@2013 by Quintessence Publishing Co Inc. and abundant bone formation around implants has led to increased attention to the surface properties of dental implants. Implants with modified surfaces are preferred when there is a need to place the implant(s) in the posterior maxilla because of poor bone quality which is commonly encountered in this area and has a negative effect on implant success. ${ }^{1,2}$ Modified implant surfaces have shown a faster bone response and higher success rates than turned surfaces in prior studies. ${ }^{3-7}$

Various methods for surface modification have been used to change the topography, chemistry, or both of the original surfaces. ${ }^{8}$ These methods include blasting and etching, anodic oxidation, plasma-sprayed hydroxyapatite $(\mathrm{HA})$ coating, and calcium phosphate $\left(\mathrm{CaPO}_{4}\right)$ coating. ${ }^{3,9-12}$ Blasted, etched, and anodized surfaces have shown high survival rates in some clinical studies. ${ }^{13-15}$ Plasma-sprayed HA-coated implants have also shown good results, but several problems, including wear of the particles and delamination of the thick coating layer, have been reported. ${ }^{9,16-22}$

Surface topography is one of the most important factors in osseointegration. The degree of an implant's surface roughness is typically divided into four categories 
based on the average height deviation $\left(\mathrm{S}_{\mathrm{a}}\right)$ value: smooth ( 0.0 to $0.4 \mu \mathrm{m})$, minimally rough $(0.5$ to $1.0 \mu \mathrm{m})$, moderately rough $(1.0$ to $2.0 \mu \mathrm{m})$, and rough $(>2.0 \mu \mathrm{m}){ }^{23} \mathrm{Ac}$ cording to Wennerberg and colleagues, a moderately roughened surface results in a stronger bone response than smoother or rougher surfaces. ${ }^{6}$

The chemical properties of the implant surface are also considered important because the chemical composition of a surface layer might influence different in vivo reactions such as reactive bond formations. The binding of proteins to the implant surface and the subsequent cell reactions could be influenced by the continuous exchange of water and various ions. ${ }^{24,25}$ To modify the surface chemistry of an implant, there have been attempts to use sodium hydroxide and heat treatment, ion implantation with calcium, or anodization with electrolytes containing phosphorus, sulfur, calcium, or magnesium ions. ${ }^{5,26-29}$

According to LeGeros, $\mathrm{CaPO}_{4}$ may form bone apatite-like mineral or carbonate $\mathrm{HA}$ on a surface, which can promote cellular function, leading to the formation of a strong bone-calcium phosphate interface that is osteoconductive and that may bind bone morphogenetic proteins to become osteoinductive. ${ }^{30} \mathrm{An}$ implant used clinically that has a thin $\mathrm{CaPO}_{4}$ coating on the acid-etched surface yielded a stronger bone response than the etched surface alone. ${ }^{11,31}$ Thus, it is expected that the combination of a thin $\mathrm{CaPO}_{4}$ coating and an anodized surface will result in a superior bone response versus a surface that has been anodized only. Unfortunately, few studies have reported on the benefits of a $\mathrm{CaPO}_{4}$-coated anodized surface.

The aim of this study, therefore, was to compare the combined $\mathrm{CaPO}_{4}$-coated anodized surface with sandblasted/acid-etched and anodized surfaces, both in vitro and in vivo. The null hypothesis of this study was that the $\mathrm{CaPO}_{4}$-coated anodized surface would not significantly differ from the other surfaces in either the in vitro or the in vivo tests.

\section{MATERIALS AND METHODS}

\section{Study Design}

Implants with four different surfaces were used in the study: turned $(T)$, sandblasted/acid-etched (SAE), anodized (A), and $\mathrm{CaPO}_{4}$-coated anodized (CPA). The $\mathrm{T}$ group was employed as a negative control, the SAE and A groups served as positive controls, and the CPA group was the experimental group. Each group comprised 11 titanium disks and six screw-type implants. Five of the 11 titanium disks of each group were used for surface characterization, and the other six titanium disks were used for an alkaline phosphatase (ALP) assay. The six screw-type implants (total $n=24$ ) were placed in six rabbits (ie, each rabbit received one implant from each group), two in each tibia, with the implant positions in each rabbit assigned randomly using $2 \times 2$ Latin squares. Half of the rabbits were sacrificed at 2 weeks after surgery, and the others were sacrificed after 4 weeks.

\section{Implant Preparation}

Twenty-four screw-type T implants made of commercially pure (grade 4) titanium (Dentium), $3.5 \mathrm{~mm}$ in diameter and $8.0 \mathrm{~mm}$ in length, were used. Forty-four titanium (grade) disks were also prepared with a diameter of $10 \mathrm{~mm}$ and a thickness of $1 \mathrm{~mm}$ (Dentium). Six implants and 11 disks without surface treatment were used as a negative control. Each of the other groups (two positive controls and one experimental group) included six implants and 11 disks with a modified surface.

\section{Surface Modification}

For the SAE surface group, the titanium surface was blasted with alumina $\left(\mathrm{Al}_{2} \mathrm{O}_{3}\right)$ particles and ultrasonically washed and dried. The sandblasted specimens were then further etched in hydrochloric acid solution. Finally, the specimens were rinsed, ultrasonically cleaned, and dried.

For the A surface group, the specimens were anodically oxidized in an aqueous electrolyte under a pulsed direct current field with a frequency of $660 \mathrm{~Hz}$. The electrolyte was prepared by dissolving $0.15 \mathrm{~mol} / \mathrm{L} \mathrm{cal-}$ cium acetate monohydrate $\left(\mathrm{Ca}\left(\mathrm{CH}_{3} \mathrm{COO}\right)_{2} \times \mathrm{H}_{2} \mathrm{O}\right)$ and $0.02 \mathrm{~mol} / \mathrm{L}$ calcium glycerophosphate $\left(\mathrm{CaC}_{3} \mathrm{H}_{7} \mathrm{O}_{6} \mathrm{P}\right)$ in deionized water. Anodic oxidation was carried out at $270 \mathrm{~V}$ for 3 minutes in a water-cooled bath. The thickness of the oxide layer was approximately $2 \mu \mathrm{m}$.

To create the CPA surface, the titanium surface was anodized as was done for the A surface specimens. The $\mathrm{CaPO}_{4}$ thin film ( 300 nm thickness) was deposited on the surface with an electron beam. The $\mathrm{CaPO}_{4}$ evaporants for the electron beam deposition were prepared by sintering a mixed hydroxyapatite (Alfa Aesar, Johnson Matthey) and calcium oxide (Sigma-Aldrich) powder at $1,000^{\circ} \mathrm{C}$ for 2 hours. Finally, the surface was heat-treated at $350^{\circ} \mathrm{C}$ for 1 hour.

\section{Surface Characterization}

Field emission scanning electron microscopy (FE-SEM) was used to view the overall surface of two disks from each group (S-4700, Hitachi). FE-SEM images were taken at four randomly selected areas on each disk. Then, with the FE-SEM images, the components and elemental content of the surfaces were analyzed with energy dispersive spectroscopy (EDS) (EX220, Horiba). Three disks from each group were used to evaluate the surface roughness. Two roughness parameters, $\mathrm{S}_{\mathrm{a}}$ and developed surface area ratio $\left(S_{d r}\right)$, were measured 
with confocal laser scanning microscopy (CLSM) (LSM 5-Pascal, Carl Zeiss). On every disk, four randomly chosen $450-\times 450-\mu \mathrm{m}$ squares were analyzed.

\section{ALP Assay}

Six disks from each group were used for the ALP assay. A cell suspension containing $5 \times 10^{3}$ preosteoblast (MC3T3/E1) cells were seeded onto the disks, which were placed in 24-well culture plates. The cells were incubated at $37^{\circ} \mathrm{C}$ in $5 \%$ carbon dioxide. The cell layers were then washed with phosphate-buffered saline and detached using a trypsin-ethylenediaminetetraacetic acid solution. After centrifugation at 1,200 rpm for 7 minutes, the cell pellets were washed once with phosphate-buffered saline and resuspended by gentle pipetting of $200 \mu \mathrm{L}$ of the ALP buffer. After centrifugation, the cell lysates were colorimetrically assayed to measure their ALP activity using p-nitrophenyl phosphate as the substrate. The reaction lasted for $30 \mathrm{~min}-$ utes at $37^{\circ} \mathrm{C}$ and was stopped by the addition of $0.05-\mathrm{N}$ sodium hydroxide. The quantity of $p$-nitrophenol produced was measured at $405 \mathrm{~nm}$ using a spectrophotometer and compared with a standard curve prepared with a p-nitrophenol standard solution. Enzyme activity was normalized to the protein concentration of the cell layer using a Bio-Rad protein assay. The activity was measured after 7 and 14 days.

\section{Animal Surgery}

This study was approved by the Animal Research Committee of Seoul National University, Seoul, Korea. All animal experiments were done in accordance with the guidelines of the Institute of Laboratory Animal Resources at Seoul National University (approval number SNU-111103-2). Six male New Zealand White rabbits (8 to 10 months old, 2.5 to $3.5 \mathrm{~kg}$ ) were used in this study. Four implants were placed in each rabbit (two in each tibia, one from each group). The positions of the implants were decided using a $2 \times 2$ Latin square design.

The rabbits were anesthetized with an intramuscular injection of $15 \mathrm{mg} / \mathrm{kg}$ tiletamine/zolazepam (Zoletil 50, Virbac Korea) and xylazine $5 \mathrm{mg} / \mathrm{kg}$ (Rompun, Bayer Korea). Prior to surgery, the shaved skin over the area of the proximal tibia was washed with betadine. A preoperative antibiotic (Cefazolin, Yuhan) was administered intramuscularly. For local anesthesia, $1.8 \mathrm{~mL}$ of $2 \%$ lidocaine (Yuhan) was injected into each surgical site. The skin was incised and each tibia was exposed following muscle dissection and periosteal elevation. The flat surface on the medial aspect of the proximal tibia was first drilled with a $2-\mathrm{mm}$ round bur at low rotational speed ( $800 \mathrm{rpm})$. The drilled hole was successively enlarged to achieve a final diameter of $3.2 \mathrm{~mm}$. The implants penetrated only the first cortical layer. The periosteum and fascia were sutured with chromic gut, and the skin was sutured with silk. Each rabbit received $0.06 \mathrm{~g}$ kanamycin intramuscularly per day for 3 days postoperatively.

\section{Histology and Histomorphometry}

After 2 and 4 weeks of healing, the rabbits were anesthetized and sacrificed with an intravenous overdose of potassium chloride. The tibia was exposed and the implants were surgically removed en bloc with an adjacent collar of bone. The specimens were immediately fixed in $4 \%$ neutral formaldehyde. The specimens were prepared to be embedded in light-curing resin (Technovit 7200 VLC, Kulzer). Undecalcified cut and ground sections were prepared using the Exakt System (Exakt) based on the method described by Donath and Breuner. ${ }^{32}$ The specimens were ground to an approximate thickness of $50 \mu \mathrm{m}$ and stained with hematoxylin and eosin. General histology was evaluated by examining the specimens under a light microscope (Olympus $\mathrm{BX}$, Olympus). Bone-to-implant contact $(\mathrm{BIC})$ ratios and bone area (BA) were calculated in four consecutive threads from the bone cortex using image analysis software (Kappa PS30C Imagebase, Kappa Optronics) connected to a light microscope.

\section{Statistical Analysis}

The mean values of the measured surface roughness parameters and the results of the ALP assay were compared among the groups by one-way analysis of variance and Tukey post hoc test. One-way analysis of variance and Tukey post hoc test were also used to determine whether BIC and BA differed significantly among the investigated surfaces. $P$ values less than .05 were considered statistically significant for all analyses.

\section{RESULTS}

\section{Surface Characterization and ALP Assay}

Figure 1 shows the FE-SEM images of the investigated surfaces. The T group exhibited parallel machining grooves, which had been produced by the manufacturing instruments. The SAE disks displayed irregularities with small micropits as a result of the grit-blasting and acid-etching procedures. Numerous open pores, from which the orifices of the larger pores protruded, were distributed on the disks. The CPA surfaces had open pores that had been produced by the anodic oxidation procedure. At higher magnification, however, a thin $\mathrm{CaPO}_{4}$ layer was observed that was not found on the $\mathrm{A}$ group disks.

The EDS analysis detected only titanium on the T and SAE disks. Oxygen, titanium, calcium, and phosphorus were found on the A and CPA disks. Table 1 summarizes the elemental content of the implant surfaces of each group. 
a
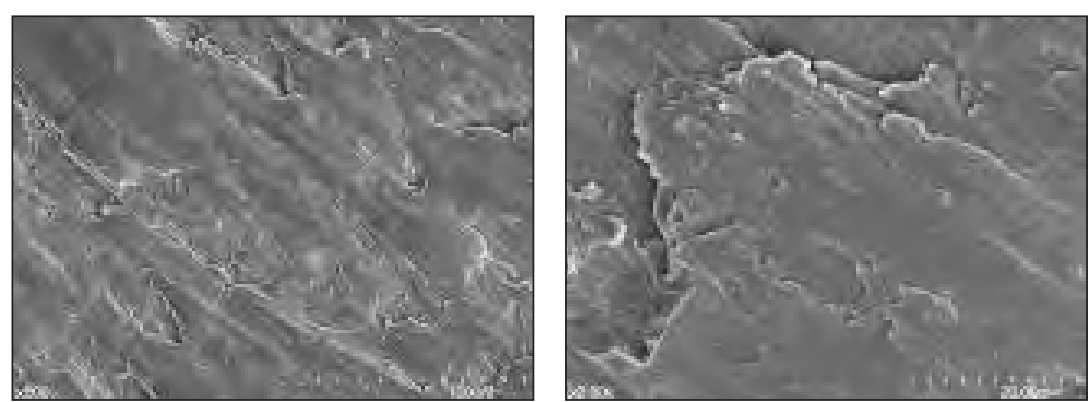

Fig 1 FE-SEM images of (a) T, (b) SAE, (c) $A$, and (d) CPA surfaces (original magnification, left to right: $\times 500, \times 2,000$, and $\times 50,000)$. Note the $\mathrm{CaPO}_{4}$-coated layer observed at $\times 50,000$ magnification (black arrows).
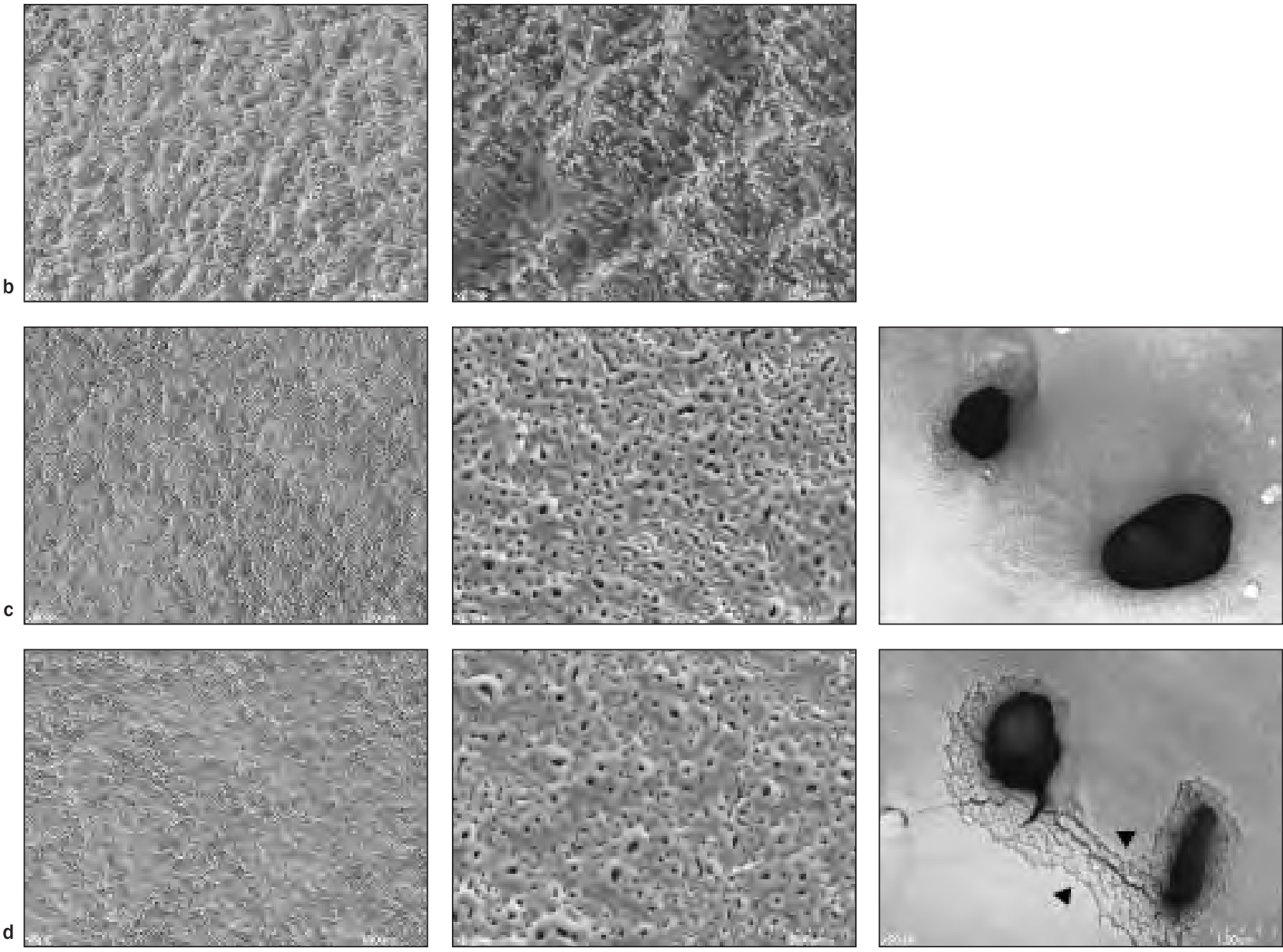

Table 1 Elemental Content (Atomic Percentages) of the Disk Surfaces as Seen with EDS

\begin{tabular}{lcccr} 
Element & T & SAE & A & CPA \\
Titanium & $100 \%$ & $100 \%$ & $39.6 \% \pm 2.8 \%$ & $17.0 \% \pm 1.1 \%$ \\
Calcium & - & - & $6.0 \% \pm 0.7 \%$ & $20.3 \% \pm 1.9 \%$ \\
\hline Phosphorus & - & - & $4.6 \% \pm 0.4 \%$ & $7.9 \% \pm 0.9 \%$ \\
Oxygen & - & - & $49.8 \% \pm 3.6 \%$ & $54.8 \% \pm 2.0 \%$ \\
\hline
\end{tabular}

The means and standard deviations (SDs) for $\mathrm{S}_{\mathrm{a}}$ were $0.32 \pm 0.03 \mu \mathrm{m}$ for the T group, $1.36 \pm 0.11 \mu \mathrm{m}$ for the SAE group, $0.68 \pm 0.02 \mu \mathrm{m}$ for the A group, and $0.67 \pm 0.11 \mu \mathrm{m}$ for the CPA group. The means and SDs for $S_{d r}$ were $3.6 \% \pm 1.5 \%$ for the T group, $56.7 \% \pm 16.1 \%$ for the SAE group, $50.9 \% \pm 2.9 \%$ for the A group, and $50.0 \% \pm 16.9 \%$ for the CPA group. The SAE group had the roughest surfaces of all the investigated surfaces $(P<.001)$. The A and CPA groups showed significantly rougher surfaces versus the negative control surface 

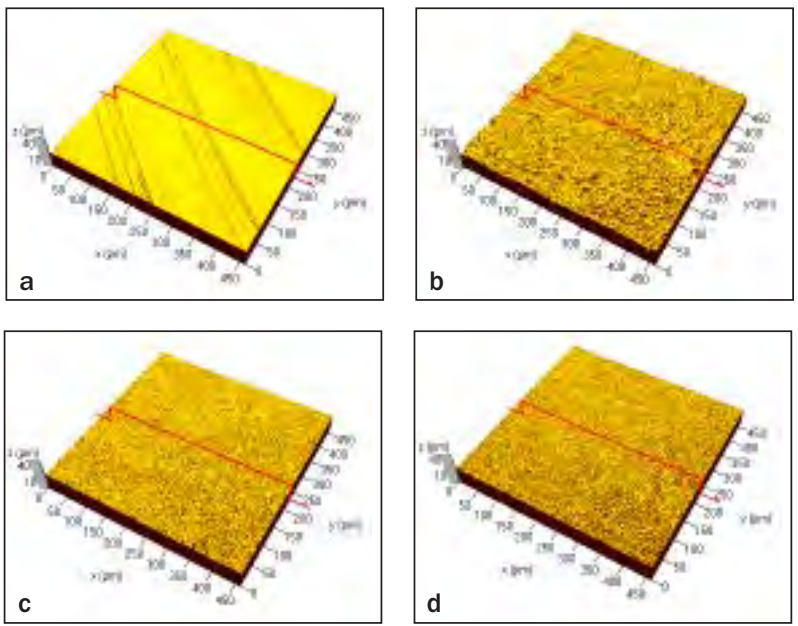

Fig 2 CLSM images of (a) T, (b) SAE, (c) A, and (d) CPA surfaces. The surface of group $T$ disks is smooth, with some shallow grooves created by machining. The SAE surface is clearly rougher than any of the other surfaces.
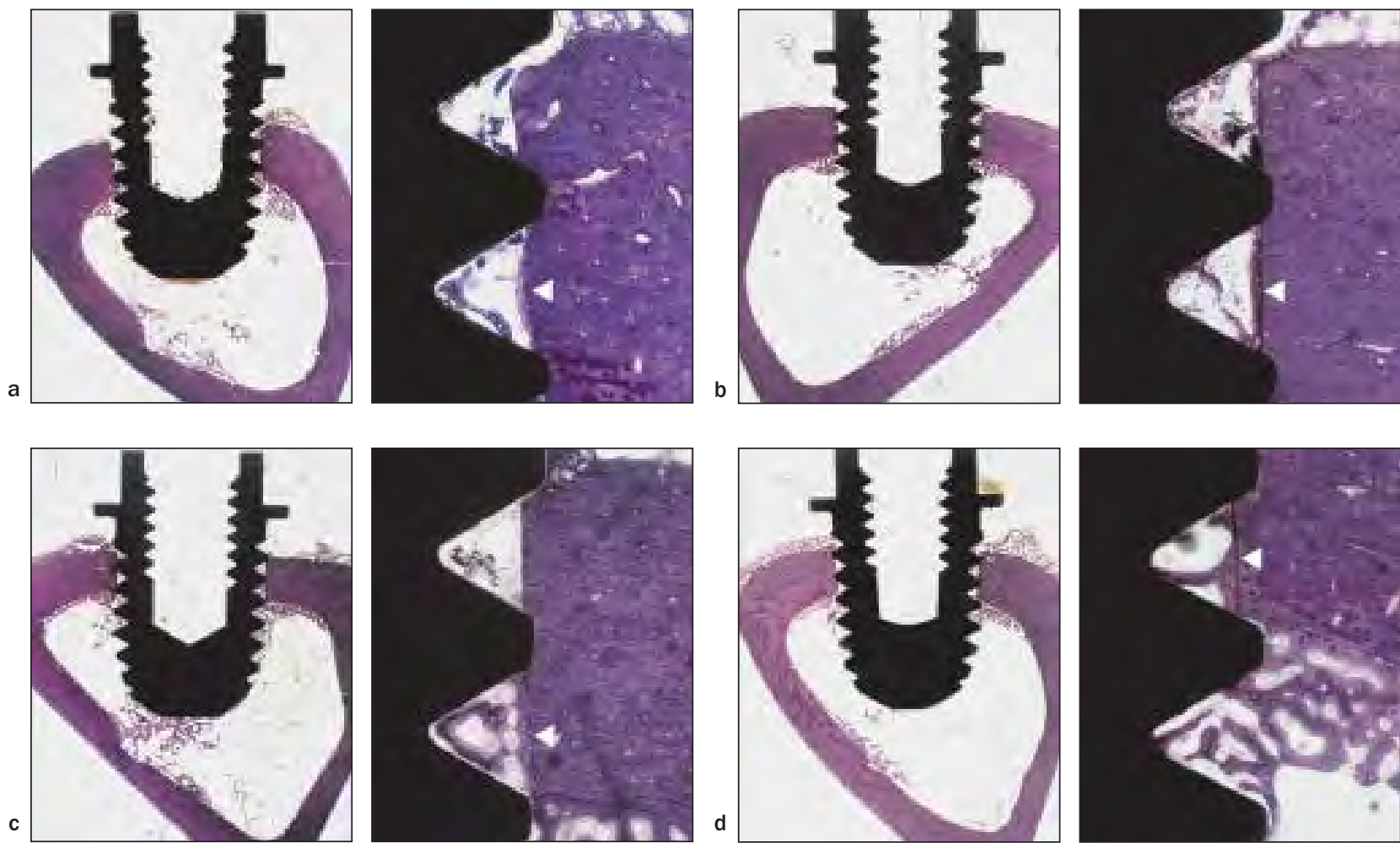

Fig 3 ALP activity of the preosteoblast cells on each surface was measured after 7 and 14 days in culture. No significant differences were found between groups.

Fig 4 Light microscopic views of the rabbit tibial bones around (a) T, (b) SAE, (c) A, and (d) CPA implants (at magnifications $\times 12.5$ and $\times 100)$. The animals were sacrificed 2 weeks after implant insertion. The border between the newly formed immature bone and the existing cortical bone can be clearly seen (white arrows).

$(P=.003)$. Analysis of the $S_{d r}$ values showed that the surface area of the experimental disks was significantly larger than that of the negative control disks $(P=.002)$. Figure 2 shows the CLSM images of the observed surfaces. There were no significant differences among the groups in terms of ALP production after either 7 or 14 days of culture (Fig 3).

\section{In Vivo Observations}

There were no complications or implant failures during the healing period. The light microscopic views of all specimens showed a significant amount of cancellous bone contacting the implant surface at the marrow area after 2 weeks of healing (Fig 4). The newly formed cortical bone was anchored to every investigated implant sur- 

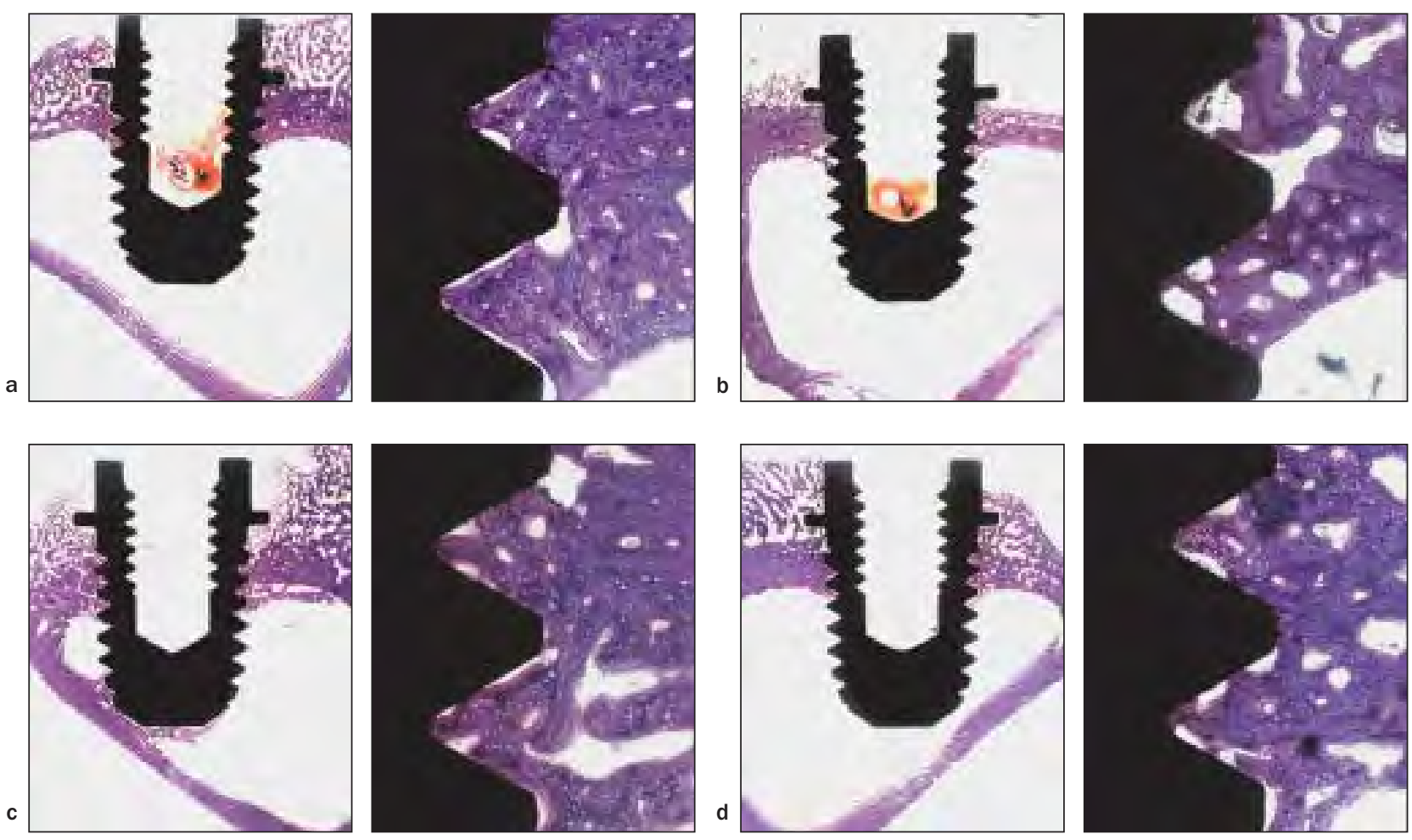

Fig 5 Light microscopic views of the rabbit tibial bones around (a) T, (b) SAE, (c) A, and (d) CPA implants (at magnifications $\times 12.5$ and $\times 100)$. The animals were sacrificed at 4 weeks after implant insertion. Mature cortical bone was now in contact with the implant surfaces.

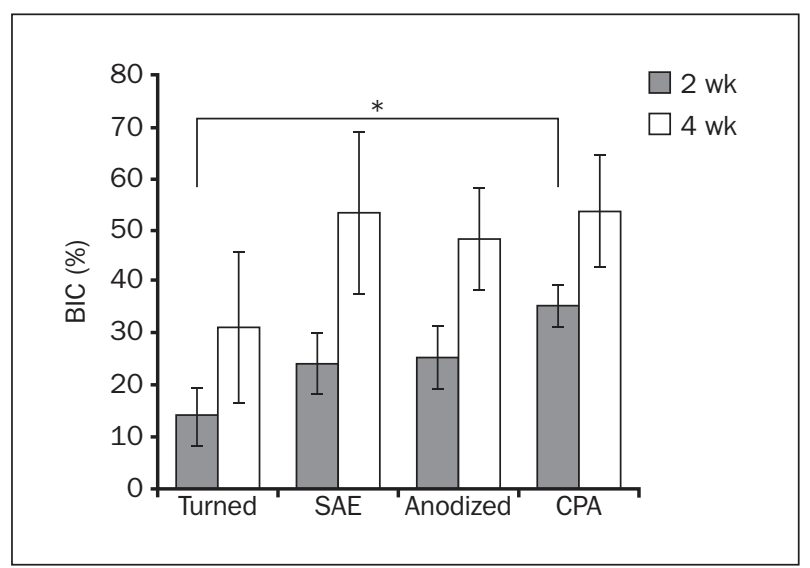

Fig 6 BIC (means and SDs) for the investigated implants after 2 and 4 weeks of healing. $* P<.05$.

face 4 weeks after implant insertion (Fig 5). No inflammatory responses were observed in any of the specimens.

At 2 weeks, the mean values and SDs for BIC were $14.0 \% \pm 5.7 \%$ for the $T$ group, $24.2 \% \pm 5.9 \%$ for the SAE group, $25.4 \% \pm 6.1 \%$ for the A group, and $35.4 \%$ $\pm 4.2 \%$ for the CPA group (Fig 6). The CPA group exhibited a significantly higher BIC ratio than the T group $(P=.006)$. Although there were no significant BIC differences among the $S A E, A$, and CPA groups, the CPA group had the highest mean value, while the SAE and $A$ groups showed higher mean values than the

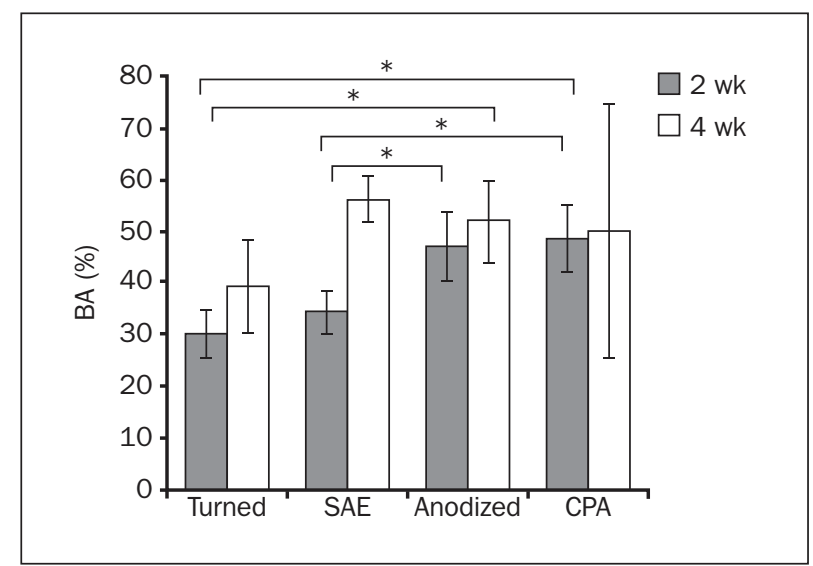

Fig 7 BA (means and SDs) for the investigated implants after 2 and 4 weeks of healing. $* P<.05$.

T group. Mean values and SDs for BIC after 4 weeks were $31.1 \% \pm 14.7 \%$ for the T group, $53.6 \% \pm 15.8 \%$ for the SAE group, $48.4 \% \pm 9.9 \%$ for the A group, and $53.7 \% \pm 10.9 \%$ for the CPA group, with no significant differences between groups $(P>.05)$ (Fig 6).

The mean values and SDs for BA were $30.3 \% \pm 4.7 \%$ for the T group, $34.4 \% \pm 4.3 \%$ for the SAE group, $47.2 \%$ $\pm 6.7 \%$ for the A group, and $48.8 \% \pm 6.6 \%$ for the CPA group after 2 weeks, while those after 4 weeks were $39.4 \% \pm 9.2 \%, 56.3 \% \pm 4.5 \%, 52.0 \% \pm 8.0 \%$, and $50.1 \%$ $\pm 24.7 \%$, respectively (Fig 7). The A and CPA groups 
showed significantly higher BA values than the others after 2 weeks $(P=.009)$. Four weeks after implant insertion, however, there were no significant differences in $B A$ values between the investigated surfaces.

\section{DISCUSSION}

The bone response to an implant surface is influenced by surface topography, surface chemistry, chemical composition, and the in vivo environment. ${ }^{8}$ In this study, a $\mathrm{CaPO}_{4}$-coated anodized surface was compared with a turned surface, an SAE surface, and an anodized surface in terms of surface topography, surface chemistry, and in vitro and in vivo responses.

The surface modification procedures resulted in a smooth surface (T group, $S_{a}=0.32 \pm 0.03 \mu \mathrm{m}$ ), two minimally rough surfaces (A and CPA groups, $S_{a}=0.68 \pm$ $0.02 \mu \mathrm{m}$ and $\mathrm{S}_{\mathrm{a}}=0.67 \mu \mathrm{m} \pm 0.11 \mu \mathrm{m}$, respectively), and a moderately rough surface (SAE group, $S_{a}=1.36 \pm$ $0.11 \mu \mathrm{m}$ ). Among these four, the roughness of the SAE surface appeared to be the most optimal for osseointegration. ${ }^{23}$ However, there was no significant difference between the modified surfaces in terms of increased surface area $\left(\mathrm{S}_{\mathrm{dr}}\right) \cdot{ }^{12,33}$

$\mathrm{CaPO}_{4}$ biomaterials, which are similar to bone mineral, are known to promote cellular function and form a strong bone- $\mathrm{CaPO}_{4}$ interface. Furthermore, $\mathrm{CaPO}_{4}$ is itself osteoconductive and may become osteoinductive by binding to bone morphogenic proteins. ${ }^{30}$ As a result, $\mathrm{CaPO}_{4}$ coating makes implant surfaces bioactive. ${ }^{23}$ Orsini and colleagues employed a calcium phosphate particle as an additive for a dual acid-etched surface to facilitate osseointegration, which resulted in a twofold higher mean BIC value versus a control surface. ${ }^{11}$ In the present study, an anodized surface was selected as a target for additional $\mathrm{CaPO}_{4}$ coating because the minimally rough surface seemed to have room for improvement in enhancing the bone-to-implant response. For the same reason, the SAE surface was employed as the positive control because it showed moderate roughness. As expected, the CPA surface enhanced bone-to-implant contact compared with the A surface. However, the degree of enhancement was not as great as that seen in the study of Orsini and colleagues.

Although the EDS analysis found compounds containing calcium and phosphorus on the anodized surface, these were from the electrolyte and differed in chemical structure and crystallinity from those found on the $\mathrm{CaPO}_{4}$ coating layer. ${ }^{5}$ Additionally, there were fewer calcium and phosphorus compounds on the anodized surface compared to the CPA surface. The chemical structure, crystallinity, and $\mathrm{CaPO}_{4}$ content appear to have an effect on the implant's affinity for bone, but the actual underlying mechanism of this affinity is unknown. ${ }^{23}$
The investigated surfaces did not differ significantly in in vitro ALP activity, which was used to evaluate osteoblastic differentiation. ${ }^{34}$ A previous study showed similar results and concluded that the effect of surface roughness on the differentiation of rat bone marrow cells is unclear. ${ }^{35}$ Another study of HA disks of different surface roughness also did not find any significant differences. ${ }^{36}$ However, a recent study showed higher ALP activity on SAE surfaces (average height deviation $\left[R_{a}\right]=3.2 \mu \mathrm{m}$ ) compared to smooth titanium surfaces $\left(R_{a}=0.2 \mu \mathrm{m}\right)$, although the SAE surfaces were much rougher than those used in the present study $(\mathrm{Ra}=1.36 \mu \mathrm{m}){ }^{37}$ The rougher blasted and anodized surfaces exhibited stronger ALP activity than the turned surface in a previous study using the osteoblastlike cell line MG63. ${ }^{38}$ It appears that surface roughness alone has no significant effect on the ALP activity of preosteoblast cells. Nonetheless, the strongest in vivo bone-implant interaction was found on the CPA surface, which was inconsistent with the findings expected from the in vitro test results. Therefore, many variables, including surface roughness, chemistry, and cell type, appear to be related to osteoblastic differentiation.

The mean BIC values from this study suggested that the modified surfaces (the SAE, A, and CPA groups) yielded an early bone response superior to that of the T group. These in vivo results are consistent with those reported in previous investigations. 5,7,39 Furthermore, the CPA group had significantly higher BIC and BA percentages than any of the other investigated modified surfaces at 2 weeks after implant placement, which indicated more rapid and abundant bone formation in the thread spaces. The differences between groups were not significant at 4 weeks, although this may have been a result of the small sample size. However, there is no evidence to refute these findings. A few studies have investigated a $\mathrm{CaPO}_{4}$-coated surface on anodized titanium oxide. One previous study dealt with a similar surface, to which the investigators applied basic fibroblast growth factor, another performed no biologic tests, and the third showed similar results. ${ }^{40-42}$

\section{CONCLUSION}

A calcium phosphate coating on an anodized surface may induce rapid osseointegration at the bone-implant interface and more bone formation near the implant surface. Furthermore, it can be postulated that a certain combination of implant surface modifications, such as calcium phosphate coating on an anodized surface, may have beneficial effects on the bone-implant interaction. However, further clinical studies are required to confirm this hypothesis. 


\section{ACKNOWLEDGMENTS}

This work was supported by the Basic Science Research Program, through the National Research Foundation of Korea, funded by the Ministry of Education, Science and Technology (no. 2011-0007662). The authors reported no conflicts of interest related to this study.

\section{REFERENCES}

1. Jaffin RA, Berman CL. The excessive loss of Brånemark fixtures in type IV bone: A 5-year analysis. J Periodontol 1991;62:2-4.

2. Zarb GA, Schmitt A. Osseointegration and the edentulous predicament. The 10-year-old Toronto study. Br Dent J 1991;170:439-444.

3. Aalam AA, Nowzari H. Clinical evaluation of dental implants with surfaces roughened by anodic oxidation, dual acid-etched implants, and machined implants. Int J Oral Maxillofac Implants 2005;20:793-798.

4. Kim YH, Koak JY, Chang IT, Wennerberg A, Heo SJ. A histomorphometric analysis of the effects of various surface treatment methods on osseointegration. Int J Oral Maxillofac Implants 2003;18:349-356.

5. Sul YT, Johansson CB, Roser K, Albrektsson T. Qualitative and quantitative observations of bone tissue reactions to anodized implants. Biomaterials 2002;23:1809-1817.

6. Wennerberg A, Albrektsson T, Andersson B. Bone tissue response to commercially pure titanium implants blasted with fine and coarse particles of aluminum oxide. Int J Oral Maxillofac Implants 1996;11:38-45.

7. Yeo IS, Han JS, Yang JH. Biomechanical and histomorphometric study of dental implants with different surface characteristics. J Biomed Mater Res B Appl Biomater 2008;87:303-311.

8. Ellingsen JE. Surface configurations of dental implants. Periodontol 2000 1998;17:36-46.

9. de Lange G, Tadjoedin E. Fate of the HA coating of loaded implants in the augmented sinus floor: A human case study of retrieved implants. Int J Periodontics Restorative Dent 2002;22:287-296.

10. Klokkevold PR, Nishimura RD, Adachi M, Caputo A. Osseointegration enhanced by chemical etching of the titanium surface. A torque removal study in the rabbit. Clin Oral Implants Res 1997;8:442-447.

11. Orsini G, Piattelli M, Scarano A, et al. Randomized, controlled histologic and histomorphometric evaluation of implants with nanometer-scale calcium phosphate added to the dual acid-etched surface in the human posterior maxilla. J Periodontol 2007;78:209-218.

12. Wennerberg A, Albrektsson T, Lausmaa J. Torque and histomorphometric evaluation of c.p. titanium screws blasted with 25- and 75-microns-sized particles of $\mathrm{Al}_{2} \mathrm{O}_{3}$. J Biomed Mater Res 1996;30: 251-260.

13. Jung UW, Choi JY, Kim CS, et al. Evaluation of mandibular posterior single implants with two different surfaces: A 5-year comparative study. J Periodontol 2008;79:1857-1863.

14. Roccuzzo M, Aglietta M, Bunino M, Bonino L. Early loading of sandblasted and acid-etched implants: A randomized-controlled double-blind split-mouth study. Five-year results. Clin Oral Implants Res 2008;19:148-152.

15. Vanden Bogaerde L, Pedretti G, Dellacasa P, Mozzati M, Rangert B, Wendelhag I. Early function of splinted implants in maxillas and posterior mandibles, using Brånemark System TiUnite implants: An 18-month prospective clinical multicenter study. Clin Implant Dent Relat Res 2004;6:121-129.

16. Geurs NC, Jeffcoat RL, McGlumphy EA, Reddy MS, Jeffcoat MK. Influence of implant geometry and surface characteristics on progressive osseointegration. Int J Oral Maxillofac Implants 2002;17:811-815.

17. Hay DI, Moreno EC. Differential adsorption and chemical affinities of proteins for apatitic surfaces. J Dent Res 1979;58:930-942.

18. Lee JJ, Rouhfar L, Beirne OR. Survival of hydroxyapatite-coated implants: A meta-analytic review. J Oral Maxillofac Surg 2000;58: 1372-1379.

19. Roynesdal AK, Ambjornsen $E$, Stovne S, Haanaes HR. A comparative clinical study of three different endosseous implants in edentulous mandibles. Int J Oral Maxillofac Implants 1998;13:500-505.
20. Rungcharassaeng K, Lozada JL, Kan JY, Kim JS, Campagni WV, Munoz CA. Peri-implant tissue response of immediately loaded, threaded, HA-coated implants: 1-year results. J Prosthet Dent 2002;87:173-181.

21. Stellino G, Landi L. A 6-year unloaded hydroxyapatite-coated dental implant placed into an extraction socket in conjunction with nonresorbable hydroxyapatite grafting material: Histologic evaluation. Int J Periodontics Restorative Dent 2002;22:575-581.

22. Sun L, Berndt CC, Gross KA, Kucuk A. Material fundamentals and clinical performance of plasma-sprayed hydroxyapatite coatings: A review. J Biomed Mater Res 2001;58:570-592.

23. Albrektsson T, Wennerberg A. Oral implant surfaces: Part 1-Review focusing on topographic and chemical properties of different surfac es and in vivo responses to them. Int J Prosthodont 2004;17:536-543.

24. Smith DC. Dental implants: Materials and design considerations. Int J Prosthodont 1993;6:106-117.

25. Williams RL, Higgins SJ, Hamnett A, Williams DF. The characteristics of protein adsorption onto metallic biomaterials. In: Heimke G, Soltesz U, Lee AJC (eds). Clinical Implant Materials, vol 9, Advances in Biomaterials. Amsterdam: Elsevier Science, 1990:327-332.

26. Kim HM, Miyaji F, Kokubo T, Nakamura T. Preparation of bioactive Ti and its alloys via simple chemical surface treatment. J Biomed Mater Res 1996;32:409-417.

27. Skripitz R, Aspenberg P. Tensile bond between bone and titanium: A reappraisal of osseointegration. Acta Orthop Scand 1998;69:315-319.

28. Sul YT, Johansson CB, Albrektsson T. Oxidized titanium screws coated with calcium ions and their performance in rabbit bone. Int J Oral Maxillofac Implants 2002;17:625-634.

29. Hanawa T. Titanium and its oxide film: A substrate for formation of apatite. In: Davies JE (ed). The Bone-Biomaterial Interface. Toronto: University of Toronto Press,1991:49-61.

30. LeGeros RZ. Properties of osteoconductive biomaterials: Calcium phosphates. Clin Orthop Relat Res 2002:81-98.

31. Goene RJ, Testori T, Trisi P. Influence of a nanometer-scale surface enhancement on de novo bone formation on titanium implants: A histomorphometric study in human maxillae. Int J Periodontics Restorative Dent 2007;27:211-219.

32. Donath K, Breuner G. A method for the study of undecalcified bones and teeth with attached soft tissues. The Sage-Schliff (sawing and grinding) technique. J Oral Pathol 1982;11:318-326.

33. Wennerberg A, Albrektsson T, Andersson B, Krol JJ. A histomorphometric and removal torque study of screw-shaped titanium implants with three different surface topographies. Clin Oral Implants Res 1995;6:24-30.

34. Turksen K, Bhargava U, Moe HK, Aubin JE. Isolation of monoclonal antibodies recognizing rat bone-associated molecules in vitro and in vivo. J Histochem Cytochem 1992;40:1339-1352.

35. Castellani R, de Ruijter A, Renggli H, Jansen J. Response of rat bone marrow cells to differently roughened titanium discs. Clin Oral Implants Res 1999;10:369-378.

36. Deligianni DD, Katsala ND, Koutsoukos PG, Missirlis YF. Effect of surface roughness of hydroxyapatite on human bone marrow cell adhesion, proliferation, differentiation and detachment strength. Biomaterials 2001;22:87-96.

37. Zhuang LF, Jiang HH, Qiao SC, et al. The roles of extracellular signalregulated kinase $1 / 2$ pathway in regulating osteogenic differentiation of murine preosteoblasts MC3T3-E1 cells on roughened titanium surfaces. J Biomed Mater Res A 2012 Jan;100(1):125-133.

38. Pae A, Kim SS, Kim HS, Woo YH. Osteoblast-like cell attachment and proliferation on turned, blasted, and anodized titanium surfaces. Int J Oral Maxillofac Implants 2011;26:475-481.

39. Wennerberg A, Hallgren C, Johansson C, Danelli S. A histomorphometric evaluation of screw-shaped implants each prepared with two surface roughnesses. Clin Oral Implants Res 1998;9:11-19.

40. Li Y, Lee IS, Cui FZ, Choi SH. The biocompatibility of nanostructured calcium phosphate coated on micro-arc oxidized titanium. Biomaterials 2008;29:2025-2032.

41. Blackwood DJ, Seah KH. Influence of anodization on the adhesion of calcium phosphate coatings on titanium substrates. J Biomed Mater Res A 2010;93:1551-1556

42. Fini M, Cigada A, Rondelli G, et al. In vitro and in vivo behaviour of Caand P-enriched anodized titanium. Biomaterials 1999;20:1587-1594. 